\title{
Mechanical Thrombectomy Access for All? Challenges in Increasing Endovascular Treatment for Acute Ischemic Stroke in the United States
}

\author{
Sushanth Rao Aroor, ${ }^{\text {a }}$ Kaiz S. Asif, ${ }^{\text {J Jennifer Potter-Vig, }}{ }^{\mathrm{c}}$ Arun Sharma, ${ }^{\mathrm{d}}$ Bijoy K. Menon, ${ }^{\mathrm{e}}$ Violiza Inoa, \\ Cynthia B. Zevallos, ${ }^{\mathrm{g}}$ Jose G. Romano, ${ }^{\text {h }}$ Santiago Ortega-Gutierrez, ${ }^{\mathrm{g}}$ Larry B. Goldstein, ${ }^{\mathrm{i}}$ \\ Dileep R. Yavagal ${ }^{\mathrm{h}, \mathrm{j}}$ \\ aDepartment of Neurology, Rutgers New Jersey Medical School, Newark, NJ, USA \\ ${ }^{b}$ Department of Neurosurgery, University of Illinois and AMITA Health, Chicago, IL, USA \\ 'Society of Vascular and Interventional Neurology, St. Cloud, MN, USA \\ 'University of Miami, Herbert Business School, Miami, FL, USA \\ ${ }^{e}$ Hotchkiss Brain Institute, Cummings School of Medicine, University of Calgary, Calgary, AB, Canada \\ fSemmes Murphey Clinic, University of Tennessee Health Science Center, Memphis, TN, USA \\ ${ }^{9}$ Department of Neurology, University of lowa Hospital and Clinics, lowa City, IA, USA \\ hDepartment of Neurology, University of Miami Miller School of Medicine, Miami, FL, USA \\ 'Department of Neurology, University of Kentucky College of Medicine, Lexington, KY, USA \\ jDepartment of Neurosurgery, University of Miami Miller School of Medicine, Miami, FL, USA
}

Mechanical thrombectomy (MT) is the most effective treatment for selected patients with an acute ischemic stroke due to emergent large vessel occlusions (LVOs). There is an urgent need to identify and address challenges in access to MT to maximize the numbers of patients who can benefit from this treatment. Barriers in access to MT include delays in evaluation and accurate diagnosis of LVO leading to inappropriate triage, logistical delays related to availability of facilities and trained interventionalists, and financial hurdles that affect treatment reimbursement. Collection of regional data related to these barriers is critical to better understand current access gaps and a measurable access score to thrombectomy could be useful to plan local public health intervention.

Keywords Stroke; Triage; Public health; Thrombectomy; Ischemic stroke; Healthcare disparities

\author{
Correspondence: Dileep R. Yavagal \\ Departments of Neurology and \\ Neurosurgery, University of Miami Miller \\ School of Medicine, 1600 NW 10th Ave \\ 1140, Miami, FL 33136, USA \\ Tel: +1-305-355-1103 \\ E-mail: dyavagal@med.miami.edu \\ https://orcid.org/0000-0003-4739-0133 \\ Received: November 6, 2021 \\ Revised: December 25, 2021 \\ Accepted: January 11, 2022
}

\section{Introduction}

Mechanical thrombectomy (MT) is the most effective treatment for acute ischemic stroke due to emergent large vessel occlusions (LVO) in appropriately selected patients. Clinical trials provide consistent evidence of improved functional outcomes and reduced mortality in patients receiving MT with a number needed to treat of 2.6. ${ }^{1}$ The numbers of patients with LVO who may benefit from MT have increased with the advent of 'tissue-based' patient selection and the extension of the 'time window' for MT to up to 24 hours for some patients. ${ }^{2,3}$ However, many eligible patients are excluded from treatment or do not receive maximal benefit of MT because of access delays. Every 10-minute delay in revascularization lowers a patient's disability-free lifetime by approximately 40 days and reduces the net monetary benefit in terms of health care costs for MT by $\$ 10,000 .{ }^{4}$ The indications for thrombectomy might further expand based on the results of ongoing studies of patients with milder strokes (low National Institutes of Health Stroke Scale [NIHSS] score strokes ${ }^{5,6}$ ) those with medium-sized 
vessel occlusion ${ }^{7}$ and those having strokes with a large ischemic core. ${ }^{8}$ There is a critical need to understand gaps to timely access to MT. This narrative review outlines important issues related to access, identifies key barriers to thrombectomy and aims to provide a framework of how to define, measure and improve access to thrombectomy for eligible patients.

\section{Measuring access}

LVOs account for approximately 30\% of all patients with acute ischemic stroke ${ }^{9}$ with studies showing prevalence ranging from $15 \%$ to $52 \% .^{10}$ Yet approximately only $3.1 \%$ of acute ischemic stroke patients received MT in 2016. ${ }^{11}$ This number increased to $8.4 \%$ among patients treated at 176 endovascular centers in $2018 .^{12}$ Despite the increasing use of MT, there continues to be a large proportion of patients who do not receive MT or receive it in a delayed fashion because of a lack of access to treatment, defined as the "timely use of personal health services to achieve the best health outcomes.."13 One of the most important considerations in measuring access is whether patients have the opportunity to benefit in those circumstances in which medical care can affect meaningful outcomes. In the context of MT, access can be measured as the ratio of the number of MT procedures performed to the total number of eligible patients. Despite the availability of national databases such as National Inpatient Sample and Get with the Guidelines, an accurate estimate of the incidence and prevalence of LVO is still challenging. There are limited data assessing LVO detection rates in patients presenting at community hospitals and primary stroke centers compared to comprehensive stroke centers (CSCs). While International Classification of Diseases 10th Revision (ICD-10) billing codes have improved stroke diagnosis with documentation of the artery involved and mechanism of stroke, they are not optimized to classify whether the stroke is LVO. ${ }^{14}$ Further, patients who have poor functional baseline or terminal cancer diagnosis would not be considered candidates for thrombectomy. To accurately measure access, a better understanding of the total number of eligible patients with LVO is needed.

\section{Barriers to access}

There are three general types of barriers to access (1) information and diagnostic access (the ability of the patient to access accurate diagnosis and treatment); (2) physical access (the ability of the patient to access health facilities geographically); and (3) financial access (the ability of the patient to pay for treatment) (Sharma A, personal communication, Pharma and Medtech in Latin America Conference, 2018). Improving access is dependent on being able to measure, monitor, and address these barriers.

\section{Information and diagnostic access}

Timely prehospital stroke recognition is an important component of overall access. There is a lost opportunity to provide critical prehospital care and appropriate rapid triage for patients who are transported to the hospital by private vehicle. Awareness of stroke symptoms is low even among high-risk patients; with the most frequently identified symptoms being unilateral weakness and slurred speech. ${ }^{15,16} \mathrm{~A}$ study showed that patients living alone are particularly susceptible to delays in seeking care with reduced thrombolysis rates ${ }^{17}$ and are therefore more likely to have lower thrombectomy rates. The use of transport services differs by race and ethnicity, with underrepresented populations less likely to utilize emergency services and less likely to call $911 .^{18}$ Public health campaigns can increase recognition of the signs and symptoms of stroke with mass media campaigns associated with the increased use of thrombolytics. ${ }^{19}$ These types of campaigns may have similar effects on increasing the timely utilization of MT.

The timely diagnosis of LVO in stroke patients presenting to the hospital is another barrier to MT. Delays in diagnosis and transfer not only lead to worse treatment outcomes but can also deprive some patients from receiving any treatment because they may become ineligible as illustrated in Figure 1. In a large, real-world prospective multicenter study of MT, the main factors associated with an increase in inter-hospital transfer times were delays in medical decision-making or the logistics of arranging transport. ${ }^{20}$ Atypical presentations such as sudden unresponsiveness due to a basilar artery occlusion may be unrecognized. ${ }^{21}$ Intracranial vascular imaging is not performed routinely at many centers as its usefulness beyond identifying thrombectomy eligibility is not well established. ${ }^{22}$ As a result, patients who have a LVO stroke with mild deficits or negative symptoms on clinical LVO scales could also be missed. The diagnosis of LVO might be increased by improved emergency medical service (EMS) and emergency department provider knowledge and assistance from tele-neurology services. Prehospital LVO scales have been developed for use by EMS to assist in triage of MT eligible patients directly to endovascular treatment (EVT) centers. ${ }^{23}$ Mobile stroke units may reduce door to needle times and can assist in triage to the most appropriate facility. ${ }^{24}$ Tele-stroke can provide an effective solution for many small or under-resourced hospitals to access acute stroke expertise and has been shown to increase thrombolysis rates. ${ }^{25}$ It could potentially increase access to MT by improving detection of LVO. It would, however, be important to determine if the 


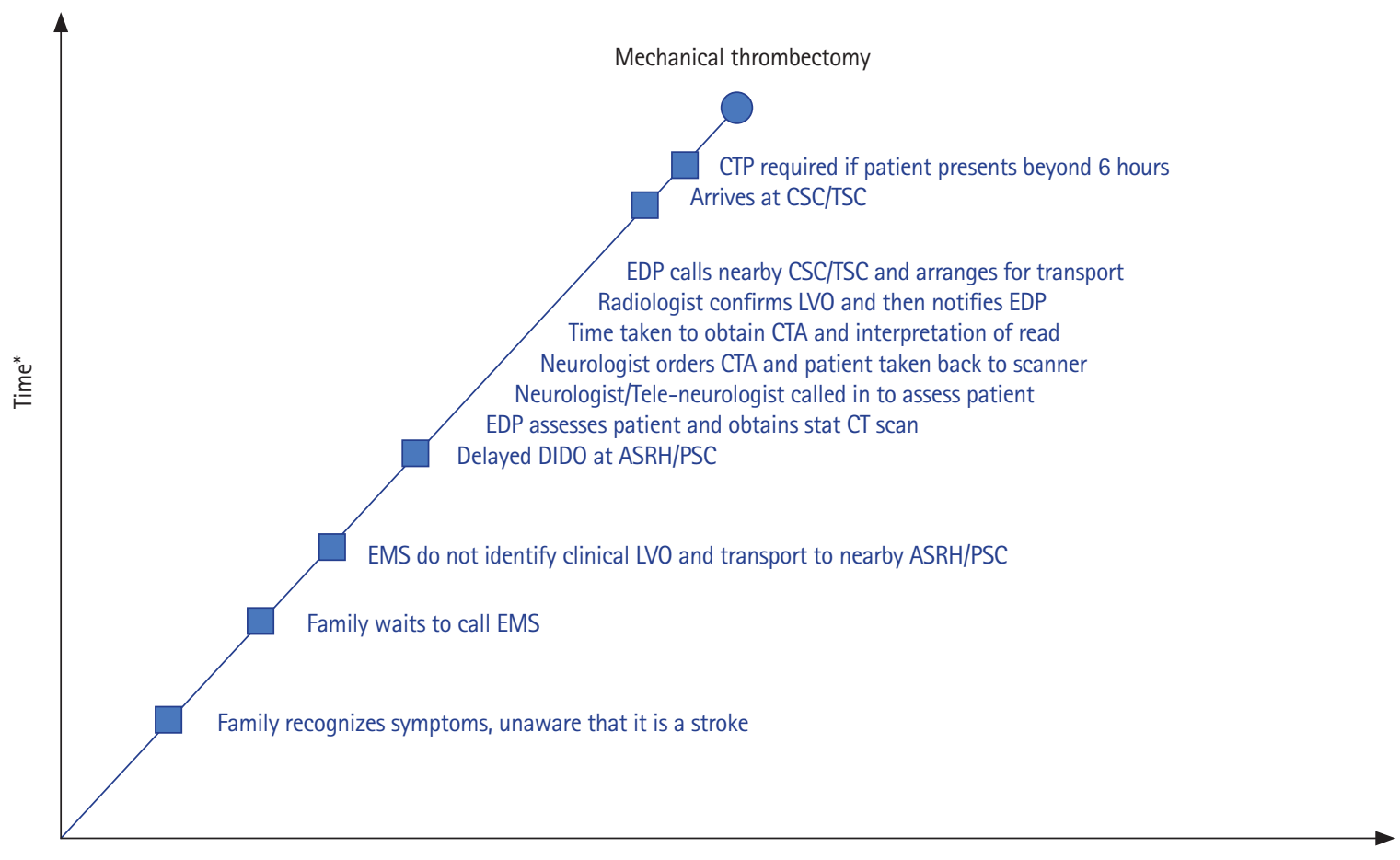

Decreased odds of $\mathrm{mRS} 0-2^{*}$

Figure 1. Factors contributing to delay in the information and diagnostic access leading to decreased odds of good functional outcome (modified Rankin Scale [mRS] 0-2) for mechanical thrombectomy. CTP, computerized tomography perfusion; CSC, comprehensive stroke center; TSC, thrombectomy capable stroke center; EDP, emergency department physician; LVO, large vessel occlusion; CTA, computed tomography angiogram; CT, computed tomography; DIDO, door in-door out; ASRH, acute stroke ready hospital; PSC, primary stroke center; EMS, emergency medical service. *Not to scale.

utilization of tele-neurology has an impact on door in-door out times. A protocol change to include a computed tomography angiogram (CTA) in addition to non-contrast computed tomography (CT) for all patients with presumed acute ischemic stroke presenting within 24 hours at a large academic center improved LVO detection and increased the frequency of MT. ${ }^{26} \mathrm{Ar}$ tificial intelligence-based software can assist in the rapid detection of LVO on CTA in eligible patients and are currently being used by some hospital systems in the United States; ${ }^{27}$ however, can be expensive for small community hospitals.

\section{Physical (geographic) access}

Access to MT varies by region in the United States. The numbers of patients undergoing MT were higher in large central metropolitan areas and lower in rural settings than the national average. The East North-Central and West South-Central regions had lower proportions of patients treated with thrombectomy. ${ }^{11}$ One-third of the United States population were beyond a 60-minute driving distance to EVT centers; $27.3 \%$ of patients were transferred to an endovascular center from a different hospital, with that percentage climbing to $44.3 \%$ among patients undergoing $\mathrm{MT}^{28}$ This study identified $713 \mathrm{EVT}$ capable centers of a total of 1,941 acute stroke ready hospitals; a center was considered EVT capable if it had submitted at least one ICD-10 code for a thrombectomy procedure in 2017 based on Center for Medicare and Medicaid Services (CMS) Medpar data. Another study that considered only 322 centers as EVT capable based on either national accreditation or state designation found that only $49.6 \%$ of United States residents had 60-minute ground access to EVT. After adding air ambulance access, that proportion rose to $62.3 \%$. In addition, of the total of 1,622 non-endovascular capable centers, only $45.4 \%$ had an endovascular capable center within a 30-minute drive. ${ }^{29}$ Another study showed patients who initially received care at non-EVT centers were substantially less likely to ultimately undergo thrombectomy than patients who initially received care at thrombectomy hubs. Rural patients had particularly limited access: $27.7 \%$ of such patients initially received care at EVT capable center versus $69.5 \%$ for urban patients. ${ }^{30}$

Geographic access can be optimized by either increasing the number of EVT centers or bypassing non-EVT centers with direct transport to the closest thrombectomy capable center. If $10 \%$ of all acute stroke-ready hospitals became EVT capable, the 30-minute access to MT could be extended to an additional 10\% of United States residents. Bypassing non-thrombectomy hospitals for direct transport to the closest thrombectomy 
capable hospital within a 15-minute additional travel time limit could lead to $>10 \%$ additional coverage for 30 states, with 9 gaining $>20 \%$ in additional population coverage. ${ }^{28}$ Each of these methods, however, could have potential negative effects. An increase in low-volume EVT hospitals could lead to sub-optimal outcomes following MT. ${ }^{31}$ Also, there may be financial obstacles with providing 24/7 neurointerventional coverage at a low volume hospital. There are a limited number of neurointerventional training positions, and without an increase in elective procedures, this number may not increase substantially. Interventionalists without formal neuroendovascular training such as interventional cardiologists and peripheral radiologists are not ideally trained to perform MT for acute stroke, and there is now a consensus among stroke professionals that those with adequate and dedicated training should perform EVT for acute stroke. ${ }^{32}$ The bypass model also has potential system-level detrimental effects. The Prehospital Stroke System of Care consensus conference recommends bypassing the closest certified stroke center if nearest CSC is within 30 minutes for patients in whom LVO is suspected. ${ }^{33} \mathrm{Al}-$ though EMS scales to identify LVO are available, the specificity for diagnosing anterior circulation LVO is approximately 50\% to $70 \%{ }^{34}$ Incorrect field LVO triage of patient's ineligible for EVT could increase the delay in receiving thrombolysis and could negatively affect their functional outcomes, unnecessarily uproot patients from their communities, and removing transport units from service for longer periods than necessary. ${ }^{35}$ This particularly holds true in rural areas as EMS providers will encounter less stroke than those in urban areas and less likely be able to keep up with prehospital triage skills. Therefore, prehospital stroke models will need to be optimized to address specific challenges facing rural and urban areas.

\section{Financial access}

The financial barrier to MT in the United States is indirect; patients receive thrombectomy regardless of their insurance status. Since the passage of the Emergency Medical Treatment and Active Labor Act (EMTALA) in $1986{ }_{1}{ }^{36}$ all hospitals accepting funds from the Center of Medicaid and Medicare are required to provide emergency medical care regardless of the patient's ability to pay. Although financial access should not be a barrier to acute stroke treatment, concerns related to personal and financial responsibility can dissuade uninsured patients from seeking immediate care. This results in disparities in access across socioeconomic, racial, and ethnic groups. The concern of not being adequately reimbursed may also dissuade hospitals from building interventional programs. From a global perspective, healthcare financing is much more complex and a major barrier in low-income and lower-middle-income countries. More than three-fourths of the total healthcare expenditure in low-income countries is derived from direct out-of-pocket payment $^{37}$ where a robust effort is needed to make MT affordable.

\section{Socioeconomic disparities}

Studies using multiple national databases show lower thrombectomy utilization rates among uninsured patients than those who have insurance. ${ }^{38}$ There does not appear to be sufficient information regarding disparities in income with regards to thrombectomy access. Patients living in low-income areas (zip code with median wealth $<39,000$ ), however, had a higher frequency of presentation to large volume EVT centers compared to those living in wealthier areas and suggests that low-income patients may live closer to an EVT center.

\section{Racial and ethnic disparities}

This remains a major issue affecting access to care and outcomes with Blacks, Hispanics, and Native Americans who have higher stroke prevalence rates compared to Whites. ${ }^{39}$ Despite the increase in the number of thrombectomy capable centers over the last 10 years, minority patients continue to have lower MT rates. ${ }^{12,40}$ Data form the National Inpatient Sample from 2016 to 2018 showed that Black/Hispanic patients' treatment rate was 2.8\% lower than White/non-Hispanic patients (7\% vs. $9.8 \%$ ). The disparity is also present among patients who presented with LVO with a 7.8\% lower utilization rate in Black/ Hispanics than White patients with a middle cerebral artery or basilar artery occlusion (35.1\% vs. $42.9 \%$ ). For patients who received intravenous alteplase, there was no significant difference in thrombectomy rates between Black/Hispanic and White patients. This could suggest a delay in presentation resulting in ineligibility for acute stroke treatments could be responsible for lower rates of MT. Black and Hispanic, male, and uninsured patients were less likely to identify stroke symptoms than White, female, and insured participants. Black/Hispanic patients also presented to thrombectomy centers directly and were less likely to be transferred from another hospital. ${ }^{41}$ This is likely due to demographic differences with Black and Hispanic patients residing nearby EVT-capable hospitals. The possibility that providers at non-EVT hospitals serving minority neighborhoods could be underdiagnosing LVO should also be considered. There are also data to suggest that there are inter-hospital transportation disparities for some race-ethnic groups when inter-hospital helicopter might be needed in rural regions. ${ }^{42}$

As uninsured patients receive thrombectomy at lower rates, factors such as reduced utilization of EMS and increased outreach to local hospitals need to be considered. Solutions in- 
Table 1. Challenges to increasing mechanical thrombectomy access and future considerations

\begin{tabular}{|c|c|c|c|c|}
\hline Barriers & Current solutions & Limitations & Future considerations & Reference \\
\hline $\begin{array}{l}\text { Information and } \\
\text { diagnostic barriers }\end{array}$ & & & & $19,23-26,45-48$ \\
\hline $\begin{array}{l}\text { Prehospital stroke } \\
\text { recognition }\end{array}$ & $\begin{array}{l}\text { Public stroke awareness } \\
\text { campaigns and EMS utilization }\end{array}$ & $\begin{array}{l}\text { Information may not reach those with } \\
\text { lower socio-economic status. }\end{array}$ & $\begin{array}{l}\text { Stroke symptoms knowledge } \\
\text { incorporated in school } \\
\text { curriculum. }\end{array}$ & \\
\hline $\begin{array}{l}\text { Underdiagnosis of } \\
\text { LVO }\end{array}$ & $\begin{array}{l}\text { Training EMS on LVO recognition } \\
\text { for appropriate stroke triage. } \\
\text { Tele-neurology at local hospital } \\
\text { may increase LVO detection. } \\
\text { Vascular imaging for all stroke } \\
\text { codes may improve detection. }\end{array}$ & $\begin{array}{l}\text { Lack of sensitivity and specificity of } \\
\text { EMS performed LVO recognition scales. } \\
\text { Time required for neurological } \\
\text { assessment by tele-provider may } \\
\text { impact door in door out. } \\
\text { 24-Hour emergency neuroradiology } \\
\text { services unavailable at many centers } \\
\text { and using Al based software for CTA } \\
\text { reads can be expensive. }\end{array}$ & $\begin{array}{l}\text { Tele-neurology in the field/ } \\
\text { ambulance to assist EMS in LVO } \\
\text { recognition and triage. } \\
\text { Sensor technology and mobile } \\
\text { stroke units with CTA for } \\
\text { prehospital LVO detection. } \\
\text { Neuro-vascular imaging training } \\
\text { and certification in LVO } \\
\text { identification for tele-neurologists } \\
\text { and cloud sharing images. }\end{array}$ & \\
\hline Physical barriers & & & & $28,29,31,33-35,49,50$ \\
\hline $\begin{array}{l}\text { Geographic access in } \\
\text { non-urban areas }\end{array}$ & $\begin{array}{l}\text { Bypass model } \\
\text { Increase in the total number of } \\
\text { thrombectomy centers. }\end{array}$ & $\begin{array}{l}\text { EMS performed LVO scales lack } \\
\text { specificity and sensitivity. } \\
\text { Concern for sub-optimal clinical } \\
\text { outcomes in low volume EVT centers. }\end{array}$ & $\begin{array}{l}\text { Above stated measures can } \\
\text { improve the accuracy of field } \\
\text { detection of LVO. } \\
\text { Transfer to nearby Neuro ICU after } \\
\text { EVT vs tele Neuro ICU } \\
\text { monitoring. }\end{array}$ & \\
\hline $\begin{array}{l}\text { Insufficient number of } \\
\text { trained } \\
\text { neurointerventionalists }\end{array}$ & Increase training programs. & $\begin{array}{l}\text { Number of non-emergent cases may be } \\
\text { insufficient. }\end{array}$ & $\begin{array}{l}\text { Interventional trained } \\
\text { Neurologists can also provide } \\
\text { stroke care to non-LVO patients. }\end{array}$ & \\
\hline Financial barriers & & & & $4,43,44,51$ \\
\hline $\begin{array}{l}\text { Cost of building } \\
\text { thrombectomy suite/ } \\
\text { program }\end{array}$ & $\begin{array}{l}\text { Increasing reimbursement may } \\
\text { incentivize hospitals to establish } \\
\text { programs. }\end{array}$ & $\begin{array}{l}\text { Analysis of cost-effectiveness is currently } \\
\text { based at the level of individual/hospital. }\end{array}$ & $\begin{array}{l}\text { System based cost analysis and } \\
\text { strategic acute stroke care } \\
\text { planning at centralized level with } \\
\text { assistance of a measurable } \\
\text { access score. }\end{array}$ & \\
\hline $\begin{array}{l}\text { Thrombectomy } \\
\text { procedural costs }\end{array}$ & $\begin{array}{l}\text { Reduce device cost and aspiration } \\
\text { technique when possible. }\end{array}$ & $\begin{array}{l}\text { Universal health care for all Americans } \\
\text { is still under progress and cost burden } \\
\text { is primarily on hospitals. }\end{array}$ & $\begin{array}{l}\text { Pursuing government policy } \\
\text { change and increased budgetary } \\
\text { provisions through an } \\
\text { organization focused on } \\
\text { increasing MT access. }\end{array}$ & \\
\hline
\end{tabular}

EMS, emergency medical service; LVO, large vessel occlusion; Al, artificial intelligence; CTA, computed tomography angiogram; EVT, endovascular treatment; ICU, intensive care unit; MT, mechanical thrombectomy.

clude increased reimbursement by the government for thrombectomy or to incentivize low volume stroke centers to develop an EVT program. Reducing the cost of stent retrievers and utilizing other cost-effective methods such as aspiration techniques could also help reduce costs and increase access. ${ }^{43}$ The responsibility for analyzing the cost benefit of developing an EVT center, however, is with the hospital. Most studies analyzing cost effectiveness of acute stroke care and MT do not address system-based stroke care costs. ${ }^{44}$

\section{Future considerations to increase access}

Although several of the discussed approaches for increasing MT access are being implemented, they have limitations (Table
1). Additional solutions to further increase access should be considered. Sensor technology for LVO detection in the ambulance shows promise. ${ }^{45}$ Software to detect LVO based on non-contrast CT is being evaluated, reducing the need to perform CTA and improving patient transfers in stroke networks. ${ }^{46}$ This maybe particularly helpful as the use of mobile stroke units continues to increase. Low-cost alternatives to mobile stroke units include ambulance based tele-neurology consultation which has been shown to reduce both door to needle and door to groin times. ${ }^{47}$ To help reduce further delays in transfer at centers where emergent neuroradiology coverage is not available, training and certifying neurologists in emergency stroke imaging should be considered with one study showing strong inter-rater reliability in LVO detection between neurolo- 
gists and neuroradiologists. ${ }^{48}$ Currently, neurointerventional training is open to neurosurgeons, neuroradiologists and vascular neurologists. Increasing the training positions available to vascular neurologists includes the advantage of them also being able to provide stroke care for patients not requiring thrombectomy in low volume EVT centers. ${ }^{49}$ Tele-intensive care unit (ICU) is an emerging field and tele-consultation with neurocritical care specialists and telemonitoring with assistance of neuro ICU nurses in hospitals without a dedicated neuro intensive care unit should be evaluated. ${ }^{50}$ The implementation of the above discussed programs is limited by financial access. Centralized planning for acute stroke care has been implemented in other countries ${ }^{51}$ and strategic planning for developing centers with EVT capabilities should be considered with cost-effective analysis being done at a system rather than a hospital level.

The Institute of Medicine uses a variety of key health indicators in its attempt to measure health care access. ${ }^{52}$ Although there are no indicators designed to measure access to any specific treatment, there may be an opportunity to develop a standardized measure for thrombectomy access, given its time sensitivity and importance in reducing long term stroke disability. While a wide range of issues that affect access to thrombectomy and acute stroke care have been identified and discussed, region specific data such as percentage of LVO patients who receive MT, median time from initial EMS contact to MT, percentage of LVO patients presenting directly to EVT capable center, rate of utilization of LVO scale by regional EMS and percentage of non-EVT capable acute stroke ready hospitals performing CTA is needed to get a better understanding of specific barriers that could be targets prioritized for improvement. In this regard, creating a measurable access score to thrombectomy may not only be a useful tool for state/local governments and public health officials to identify gaps in stroke MT access, but also improve stroke systems of care with the goal of optimizing patient outcomes and reducing health care costs.

\section{Conclusions}

The burden of stroke is a critical health care problem and timely access to MT reduces both mortality and long-term morbidity. Despite an increase in MT access in the United States, there are inequities in access to timely EVT for specific populations. Although progress has been made to address challenges regarding access, gaps in knowledge and systems remain. Those gaps are likely to be even more pronounced in countries with limited resources. Additional studies are needed to better understand the access gap that exists today which should be an important area of focus for public health officials and stroke organizations.

\section{Novelty and significance}

- Aims to classify barriers to Mechanical thrombectomy into three specific barriers: information and diagnostic access, financial access as well as geographic and physical access.

- Aims to provide a framework to define, measure and expand MT access in the United States.

- Identify challenges associated with access in the United States and offer potential solutions.

- While there are limited articles focusing on individual aspects of thrombectomy access in the United States, no comprehensive review is available to our knowledge on this topic that discusses all of the above barriers.

\section{Disclosure}

Dileep R. Yavagal is on the steering committee of TIGER clinical trial sponsored by Rapid Medical and steering committee of CALM-2 sponsored by Vascular Dynamics. He is a consultant to Medtronic, Cerenovus, Poseydon, Neurosave, and other Neuralanalytics. The other authors have no financial conflicts of interest.

\section{References}

1. Goyal M, Menon BK, van Zwam WH, Dippel DW, Mitchell PJ, Demchuk AM, et al. Endovascular thrombectomy after large-vessel ischaemic stroke: a meta-analysis of individual patient data from five randomised trials. Lancet 2016;387: 1723-1731.

2. Albers GW, Lansberg MG, Kemp S, Tsai JP, Lavori P, Christensen $S$, et al. A multicenter randomized controlled trial of endovascular therapy following imaging evaluation for ischemic stroke (DEFUSE 3). Int J Stroke 2017;12:896-905.

3. Nogueira RG, Jadhav AP, Haussen DC, Bonafe A, Budzik RF, Bhuva $P$, et al. Thrombectomy 6 to 24 hours after stroke with a mismatch between deficit and infarct. N Engl J Med 2018; 378:11-21.

4. Kunz WG, Hunink MG, Almekhlafi MA, Menon BK, Saver JL, Dippel DWJ, et al. Public health and cost consequences of time delays to thrombectomy for acute ischemic stroke. Neurology 2020;95:e2465-e2475.

5. Nagel S, Bouslama M, Krause LU, Küpper C, Messer M, Pe-

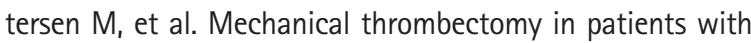
milder strokes and large vessel occlusions. Stroke 2018;49: 
2391-2397.

6. Sarraj A, Hassan AE, Grotta J, Sitton C, Cutter G, Cai C, et al. Optimizing patient selection for endovascular treatment in acute ischemic stroke (SELECT): a prospective, multicenter cohort study of imaging selection. Ann Neurol 2020;87:419433.

7. Goyal M, Ospel JM, Menon BK, Hill MD. MeVO: the next frontier? J Neurointerv Surg 2020;12:545-547.

8. Sarraj A, Grotta JC, Pujara DK, Shaker F, Tsivgoulis G. Triage imaging and outcome measures for large core stroke thrombectomy: a systematic review and meta-analysis. J Neurointerv Surg 2020;12:1172-1179.

9. Lakomkin N, Dhamoon M, Carroll K, Singh IP, Tuhrim S, Lee J, et al. Prevalence of large vessel occlusion in patients presenting with acute ischemic stroke: a 10-year systematic review of the literature. J Neurointerv Surg 2019;11:241-245.

10. Waqas $M$, Rai AT, Vakharia $K$, Chin $F$, Siddiqui AH. Effect of definition and methods on estimates of prevalence of large vessel occlusion in acute ischemic stroke: a systematic review and meta-analysis. J Neurointerv Surg 2020;12:260-265.

11. MacKenzie IER, Moeini-Naghani I, Sigounas D. Trends in endovascular mechanical thrombectomy in treatment of acute ischemic stroke in the United States. World Neurosurg 2020; 138:e839-e846.

12. Rinaldo L, Rabinstein $A A$, Cloft $H$, Knudsen JM, Castilla LR, Brinjikji W. Racial and ethnic disparities in the utilization of thrombectomy for acute stroke. Stroke 2019;50:2428-2432.

13. Institute of Medicine (US) Committee on Monitoring Access to Personal Health Care Services. Access to Health Care in America. Washington, DC: National Academies Press (US), 1993.

14. Zachrison KS, Li S, Reeves MJ, Adeoye O, Camargo CA, Schwamm LH, et al. Strategy for reliable identification of ischaemic stroke, thrombolytics and thrombectomy in large administrative databases. Stroke Vasc Neurol 2021;6:194200.

15. Ojike N, Ravenell J, Seixas A, Masters-Israilov A, Rogers A, Jean-Louis $G$, et al. Racial disparity in stroke awareness in the US: an analysis of the 2014 National Health Interview Survey. J Neurol Neurophysiol 2016;7:365.

16. Goldstein LB, Silberberg M, McMiller Y, Yaggy SD. Stroke-related knowledge among uninsured Latino immigrants in Durham County, North Carolina. J Stroke Cerebrovasc Dis 2009;18:229-231.

17. Reeves MJ, Prager M, Fang J, Stamplecoski M, Kapral MK. Impact of living alone on the care and outcomes of patients with acute stroke. Stroke 2014;45:3083-3085.

18. Mochari-Greenberger $H$, Xian $Y$, Hellkamp AS, Schulte PJ,
Bhatt DL, Fonarow GC, et al. Racial/ethnic and sex differences in emergency medical services transport among hospitalized US stroke patients: analysis of the National Get With The Guidelines-Stroke Registry. J Am Heart Assoc 2015;4:e002099.

19. Payne GH, Fang J, Fogle CC, Oser CS, Wigand DA, Theisen V, et al. Stroke awareness: surveillance, educational campaigns, and public health practice. J Public Health Manag Pract 2010;16:345-358.

20. Froehler MT, Saver JL, Zaidat 00, Jahan R, Aziz-Sultan MA, Klucznik RP, et al. Interhospital transfer before thrombecto$\mathrm{my}$ is associated with delayed treatment and worse outcome in the STRATIS Registry (Systematic Evaluation of Patients Treated With Neurothrombectomy Devices for Acute Ischemic Stroke). Circulation 2017;136:2311-2321.

21. Organek N, Milano N, Donohue M, Sundararajan S, Strbian D, Katzan IL. Significant period between presentation and diagnosis in basilar artery occlusion: five cases and the lessons learned. Stroke 2015;46:e79-e81.

22. Powers WJ, Rabinstein AA, Ackerson T, Adeoye OM, Bambakidis NC, Becker K, et al. 2018 Guidelines for the early management of patients with acute ischemic stroke: a guideline for healthcare professionals from the American Heart Association/American Stroke Association. Stroke 2018;49:e46-e110.

23. Lima FO, Silva GS, Furie KL, Frankel MR, Lev MH, Camargo ÉC, et al. Field assessment stroke triage for emergency destination: a simple and accurate prehospital scale to detect large vessel occlusion strokes. Stroke 2016;47:1997-2002.

24. Ehntholt MS, Parasram M, Mir SA, Lerario MP. Mobile stroke units: bringing treatment to the patient. Curr Treat Options Neurol 2020;22:5.

25. Amorim E, Shih MM, Koehler SA, Massaro LL, Zaidi SF, Jumaa $M A$, et al. Impact of telemedicine implementation in thrombolytic use for acute ischemic stroke: the University of Pittsburgh Medical Center telestroke network experience. J Stroke Cerebrovasc Dis 2013;22:527-531.

26. Mayer SA, Viarasilpa T, Panyavachiraporn N, Brady M, Scozzari $D$, Van Harn $M$, et al. CTA-for-All: impact of emergency computed tomographic angiography for all patients with stroke presenting within 24 hours of onset. Stroke 2020;51: 331-334.

27. Sheth SA, Lopez-Rivera V, Barman A, Grotta JC, Yoo A, Lee $S$, et al. Machine learning-enabled automated determination of acute ischemic core from computed tomography angiography. Stroke 2019;50:3093-3100.

28. Sarraj A, Savitz S, Pujara D, Kamal H, Carroll K, Shaker F, et al. Endovascular thrombectomy for acute ischemic strokes: current US access paradigms and optimization methodology. Stroke 2020;51:1207-1217. 
29. Aldstadt J, Waqas M, Yasumiishi M, Mokin M, Tutino VM, Rai $\mathrm{HH}$, et al. Mapping access to endovascular stroke care in the USA and implications for transport models. J Neurointerv Surg 2022;14:neurintsurg-2020-016942.

30. Kamel H, Parikh NS, Chatterjee A, Kim LK, Saver JL, Schwamm $\mathrm{LH}$, et al. Access to mechanical thrombectomy for ischemic stroke in the United States. Stroke 2021;52:2554-2561.

31. Kim BM, Baek JH, Heo JH, Kim DJ, Nam HS, Kim YD. Effect of cumulative case volume on procedural and clinical outcomes in endovascular thrombectomy. Stroke 2019;50:1178-1183.

32. Lavine SD, Cockroft $K$, Hoh $B$, Bambakidis $N$, Khalessi $A A$, Woo $\mathrm{H}$, et al. Training guidelines for endovascular ischemic stroke intervention: an international multi-society consensus document. AJNR Am J Neuroradiol 2016;37:E31-E34.

33. Jauch EC, Schwamm LH, Panagos PD, Barbazzeni J, Dickson $R$, Dunne $R$, et al. Recommendations for regional stroke destination plans in rural, suburban, and urban communities from the Prehospital Stroke System of Care Consensus Conference: a consensus statement from the American Academy of Neurology, American Heart Association/American Stroke Association, American Society of Neuroradiology, National Association of EMS Physicians, National Association of State EMS Officials, Society of Neurolnterventional Surgery, and Society of Vascular and Interventional Neurology: endorsed by the Neurocritical Care Society. Stroke 2021;52:e133-e152.

34. Smith EE, Kent DM, Bulsara KR, Leung LY, Lichtman JH, Reeves MJ, et al. Accuracy of prediction instruments for diagnosing large vessel occlusion in individuals with suspected stroke: a systematic review for the 2018 guidelines for the early management of patients with acute ischemic stroke. Stroke 2018;49:e111-e122.

35. Southerland AM, Johnston KC, Molina CA, Selim MH, Kamal N, Goyal M. Suspected large vessel occlusion: should emergency medical services transport to the nearest primary stroke center or bypass to a comprehensive stroke center with endovascular capabilities? Stroke 2016;47:1965-1967.

36. Zibulewsky J. The Emergency Medical Treatment and Active Labor Act (EMTALA): what it is and what it means for physicians. Proc (Bayl Univ Med Cent) 2001;14:339-346.

37. Waters $H$. Health financing for poor people: resource mobilization and risk sharing. Bull World Health Organ 2005;83:236.

38. Brinjikji W, Rabinstein AA, McDonald JS, Cloft HJ. Socioeconomic disparities in the utilization of mechanical thrombectomy for acute ischemic stroke in US hospitals. AJNR Am J Neuroradiol 2014;35:553-556.

39. Centers for Disease Control and Prevention (CDC). Prevalence of stroke: United States, 2006-2010. MMWR Morb Mortal Wkly Rep 2012;61:379-382.
40. Attenello FJ, Adamczyk P, Wen G, He S, Zhang K, Russin JJ, et al. Racial and socioeconomic disparities in access to mechanical revascularization procedures for acute ischemic stroke. J Stroke Cerebrovasc Dis 2014;23:327-334.

41. Bouslama M, Rebello LC, Haussen DC, Grossberg JA, Anderson AM, Belagaje SR, et al. Endovascular therapy and ethnic disparities in stroke outcomes. Interv Neurol 2018;7:389-398.

42. Vaughan Sarrazin $M$, Limaye $K$, Samaniego EA, Al Kasab $S$, Sheharyar A, Dandapat $S$, et al. Disparities in inter-hospital helicopter transportation for hispanics by geographic region: a threat to fairness in the era of thrombectomy. J Stroke Cerebrovasc Dis 2019;28:550-556.

43. Malhotra A, Boltyenkov A, Wu X, Matouk CC, Forman HP, Gandhi $D$, et al. Endovascular contact aspiration versus stent retriever for revascularization in patients with acute ischemic stroke and large vessel occlusion: a cost-minimization analysis. World Neurosurg 2020;139:e23-e31.

44. Guzauskas GF, Boudreau DM, Villa KF, Levine SR, Veenstra DL. The cost-effectiveness of primary stroke centers for acute stroke care. Stroke 2012;43:1617-1623.

45. Walsh KB. Non-invasive sensor technology for prehospital stroke diagnosis: current status and future directions. Int $J$ Stroke 2019;14:592-602.

46. Olive-Gadea $M$, Crespo $C$, Granes $C$, Hernandez-Perez $M$,

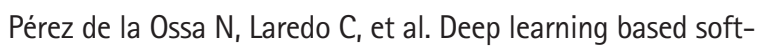
ware to identify large vessel occlusion on noncontrast computed tomography. Stroke 2020;51:3133-3137.

47. Al Kasab S, Almallouhi E, Grant C, Hewitt D, Hewitt J, Baki $M$, et al. Telestroke consultation in the emergency medical services unit: a novel approach to improve thrombolysis times. J Stroke Cerebrovasc Dis 2021;30:105710.

48. Bar M, Kral J, Jonszta T, Marcian V, Kuliha M, Mikulik R. Interrater variability for CT angiography evaluation between neurologists and neuroradiologist in acute stroke patients. $\mathrm{Br}$ J Radiol 2017;90:20160670.

49. Grotta JC, Lyden P, Brott T. Rethinking training and distribution of vascular neurology interventionists in the era of thrombectomy. Stroke 2017;48:2313-2317.

50. Rincon F, Vibbert $M$, Childs V, Fry R, Caliguri D, Urtecho J, et al. Implementation of a model of robotic tele-presence (RTP) in the neuro-ICU: effect on critical care nursing team satisfaction. Neurocrit Care 2012;17:97-101.

51. Ramsay Al, Morris S, Hoffman A, Hunter RM, Boaden R, McKevitt $C$, et al. Effects of centralizing acute stroke services on stroke care provision in two large metropolitan areas in England. Stroke 2015;46:2244-2251.

52. Koh HK, Blakey CR, Roper AY. Healthy people 2020: a report card on the health of the nation. JAMA 2014;311:2475-2476. 